\title{
REDUÇÃO DE NÃO CONFORMIDADES ATRAVÉS DA APLICAÇÃO DA
}

\author{
METODOLOGIA DMAIC
}

\author{
André Luiz Emmel Silva ${ }^{1}$ \\ https://orcid.org/0000-0003-2499-1104 \\ Daniel Augusto Hoppe ${ }^{2}$ \\ Ezequiel Augusto Kaufmann ${ }^{3}$ \\ https://orcid.org/0000-0003-2230-3590 \\ Paulo Ricardo Losekann II \\ https://orcid.org/0000-0002-9423-3686 \\ Jorge André Ribas de Moraes ${ }^{5}$ \\ https://orcid.org/0000-0002-9505-8883
}

Recebido em: 5 jun. 2020

Aceito em: 14 dez. 2020

Como citar este artigo: EMMEL SILVA, A. L.; HOPPE, D. A.; KAUFMANN, E. A.; LOSEKANN II, P. R.; RIBAS DE MORAES, J. A. REDUÇÃO DE NÃO CONFORMIDADES ATRAVÉS DA APLICAÇÃO DA METODOLOGIA DMAIC: REDUCTION OF THE OCCURRENCE OF NONCONFORMITIES THROUGH THE APPLICATION OF DMAIC METHODOLOGY. Revista Visão: Gestão Organizacional, Caçador (SC), Brasil, v. 9, n. 2, p. 206-223, 2020. Disponível em: 10.33362/visao.v9i2.2292.

Resumo: De acordo com dados repassados pelo setor financeiro de uma empresa do ramo de refrigeração comercial, observou-se que dentre os custos evitáveis da organização, a maior parcela acontece devido à assistência técnica prevista na garantia dos produtos. Nesse contexto, em meio a um período de economia nacional instável, busca-se mais do que nunca cortes de custos em geral, a fim de que a empresa se mantenha competitiva no mercado. Propôs-se, então, implantar métodos para diminuir as ocorrências no SAC. Dentre o contexto de controle total de qualidade, a principal ferramenta usada é a DMAIC, a qual consiste em definir o problema, mensurar os dados e analisá-los, melhorar o processo e controlá-lo. Observou-se, para isto, as maiores incidências do SAC, tais como vazamentos de gás, instruções de uso, problemas de montagem, sistema de iluminação e barulhos no motor. Houve, portanto, o intuito de dar maior atenção àquelas que representam maior número de incidências. Estas ocorrências foram trabalhadas de acordo com o DMAIC, melhorando o produto, reduzindo custos e aumentando a satisfação do cliente.

PALAVRAS-CHAVE: SAC, Qualidade, DMAIC, Custos de Qualidade, Melhorias.

REDUCTION OF THE OCCURRENCE OF NONCONFORMITIES THROUGH THE APPLICATION

\footnotetext{
${ }^{1}$ Mestre em Tecnologia Ambiental, Universidade de Santa Cruz do Sul, andresilva@unisc.br.

2 Mestre em Engenharia de Produção, Universidade de Santa Cruz do Sul, danielhoppe@unisc.br.

${ }^{3}$ Acadêmico de Engenharia de Produção, Universidade de Santa Cruz do Sul, ezequielkaufmann@gmail.com.

${ }^{4}$ Engenheiro de Produção, Universidade de Santa Cruz do Sul, paulolosekann@gmail.com.

${ }^{5}$ Universidade de Santa Cruz do Sul-UNISC. E-mail: jorge@unisc.br.
} 


\section{OF DMAIC METHODOLOGY}

Abstract: According to the data collected by the financial department of a company of the commercial refrigeration sector, it was observed that among the avoidable costs of an organization, the largest share is related to the technical assistance provided during after-sales services. In this context, in the midst of a period of unstable national economy, we seek more than ever to cut costs in general, so that the company remains competitive in the market. Therefore, it was proposed the use of quality tools aiming to reduce the number of after-sales assistances. Within the context of total quality control, a major tool is DMAIC, which consists in defining a problem, measuring and analyzing the data, improving and controlling the process. In order to apply it, the problems with the greatest number of incidences were analyzed, such as gas leaks, operating instructions, assembling problems, lighting system and compressor noise. Thus, it was aimed to pay greater attention to the problems that represent the greatest share of the incidences. The occurrences were addressed in accordance to DMAIC, improving the product, reducing costs and increasing customer satisfaction.

KEYWORDS: Customer Service, Quality, DMAIC, Quality Costs, Improvements.

\section{INTRODUÇÃO}

Segundo Seleme e Stadler (2010), uma empresa, ao longo de sua trajetória, sempre busca um meio para a sua manutenção no ramo de negócio. Entretanto, isso somente se dá devido às exigências daqueles que compõem o mercado consumidor. Nesse sentido, Juran (1988) afirma que, com tamanho fluxo de informações, novos concorrentes, e crescente globalização, qualidade ainda é fundamental no que tange à permanência no mercado. Trabalhar-se-á, portanto, o conceito da gestão da qualidade com fundamentação na opinião e dados levantados pelos clientes, de acordo com o Serviço de Atendimento ao Consumidor (SAC). O SAC, como salienta Miguel (2010), é uma ferramenta para mensurar os dados, o que garante que não há subjetivismo e influência pessoal na abordagem do trabalho.

No tocante à opinião dos clientes desta empresa de refrigeração, há um considerável índice de reclamações acerca dos defeitos e não conformidades observadas em relação aos produtos. Nesse âmbito, Cierco et al. (2011), sugerem que a qualidade nada mais é do que a competência de um produto suprir as necessidades e propósitos daqueles que o adquirem.

Sendo assim, este trabalho se baseia no alto índice de assistência técnica dos produtos de uma indústria do ramo de refrigeração. Com auxílio da ferramenta SAC (Serviço de Atendimento ao Consumidor) e do serviço de pós-venda, foi possível levantar dados de não conformidades ou defeitos observados pelos clientes. Usou-se como referência um período de dois anos (março de 2014 à março de 2016), considerando-se que defeitos reclamados anteriormente a este período possivelmente já foram trabalhados e corrigidos. Para as reclamações observadas pelos clientes, depois de catalogadas e analisadas pelo SAC, é demandada assistência técnica (segundo termos de garantia dos produtos vendidos) para 
qualquer parte do país.

Inicialmente, a intenção foi focar nos produtos líderes de venda da empresa. No entanto, constatou-se que dentre estes, apesar das características e finalidades distintas, os tipos de reclamações e defeitos eram, em geral, os mesmos. Instruções de uso, vazamentos de gás, problemas de montagem, sistema de iluminação e barulhos no motor estão dentre os mais citados nas linhas de produtos em geral, e correspondem a aproximadamente $70 \%$ do total dos problemas observados, logo, serão o foco do trabalho.

\section{MATERIAIS E MÉTODOS}

A empresa em estudo foi fundada em 1999 na região central do Estado do Rio Grande do Sul, onde se localiza até hoje, num prédio com cerca de 10 mil metros quadrados e 390 funcionários, sendo 298 no meio produtivo e 92 nas partes administrativas e de engenharia. Atualmente a capacidade produtiva gira em torno de 150 produtos ao dia, de todos os gêneros de refrigeradores comerciais. Desde câmaras frias, expositores para açougue, buffets de sorvete, expositores ilha, freezers horizontais, freezers verticais, e expositores para confeitarias.

Para formulação deste trabalho foram feitas pesquisas bibliográficas com o fim de analisar melhor método para se trabalhar. Após, fez-se pesquisa documental nos registros da empresa para se poder tabular e definir produtos foco para aplicação do trabalho. Gil (2010) ao tratar de pesquisa bibliográfica, salienta a importância àquele que pesquisa, visto que podem-se assimilar informações de variados autores. Desta forma, crê que se adquire conhecimento pesquisando diversas fontes, pois um autor pode contrapor ou corroborar o outro, o que implica em questionamentos.

Este trabalho enquadra-se na definição de pesquisa quali-quantitativa. Segundo Miguel et al. (2010), juntamente com o estudo de caso, o método desta pesquisa, conhecido como pesquisa-ação, é o mais adequado. Rodrigues (2010) salienta que uma pesquisa-ação eficaz no que tange um trabalho em gestão da qualidade deve seguir diretrizes específicas. Após claro diagnóstico da situação que será trabalhada, aplicam-se as diretrizes para a pesquisa: (i) Definição dos temas e problemas prioritários; (ii) Elaboração da problemática na qual serão tratados os problemas; (iii) Coordenação das atividades em sintonia com outros grupos da organização; (iv) Centralização de informações provenientes de diversas fontes; (v) Interpretação dos resultados; (vi) Busca de soluções e propostas de ações; (vii) Acompanhamento das ações implementadas e avaliação de resultados; e (viii) Divulgação de resultados pelos canais apropriados. 


\section{FUNDAMENTAÇÃO TEÓRICA}

O mercado mundial de refrigeração comercial foi avaliado em 27 bilhões de dólares no ano de 2018 e projeta-se um crescimento de $4,1 \%$ ao ano até 2026 , chegando ao valor de 37 bilhões de dólares. Esse crescimento constante ocorre devido à demanda crescente por produtos congelados/resfriados, causada principalmente pela rápida urbanização e por mudanças no estilo de vida dos consumidores (KUMAR \& DESHMUKH, 2019). Além disso, acredita-se que esse aumento de mercado se dá em função da expectativa de novos empreendimentos do ramo alimentício, bem como crescimento das atividades de turismo (TRANSPARENCY MARKET RESEARCH, 2013). Desta forma, Gava, Farias e Silva (2009) salientam que a indústria alimentícia no Brasil em qualquer escala não corre os riscos da atual economia instável, pois, a alimentação sempre será de primeira necessidade ao ser humano. Partindo-se deste pressuposto, indústrias de produtos e acessórios visados ao ramo (como fornos, refrigeração, etc.) também estão atrelados a esta segurança econômica.

\section{GESTÃO DA QUALIDADE}

Segundo Carvalho et al. (2005), a gestão da qualidade consiste no conjunto de atividades coordenadas para dirigir e controlar uma organização com relação à qualidade, englobando o planejamento, o controle, a garantia e a melhoria da qualidade. A gestão da qualidade permite que os participantes desenvolvam seus potenciais e atinjam seus objetivos através da cooperação e aprendizado para assim contribuir positivamente na performance da organização (STEFAN \& IVONNE, 2012). Além de focar em atender/exceder as expectativas dos clientes, as filosofias de gestão da qualidade buscam também atender as expectativas de outros stakeholders importantes para uma organização, tais como órgãos reguladores, fornecedores e a comunidade (BASTAS et al., 2018).

Qualidade não é um fator que depende meramente da empresa e seus colaboradores. Não há porque se falar em qualidade em um produto, se não há qualidade no fornecedor. Por exemplo, se a matéria prima comprada não é conforme, provavelmente o produto final também não será. Os sistemas do fornecedor e comprador devem funcionar com entendimento e cooperação, um deve respeitar o processo e limitações do outro. O fornecedor pode não garantir o padrão e qualidade de seus produtos, o que ocorre muitas vezes com micro e pequenas empresas, normalmente com processos artesanais. Nestes casos, a empresa que efetua a compra, se não houver outra empresa fornecedora, deve designar funcionário para averiguação da mercadoria, e, se necessário, recusar o lote (FALCONI, 2014). O gerenciamento da qualidade da cadeia de suprimentos é uma área de pesquisa emergente, a qual incorpora práticas de gestão da cadeia de suprimentos e de gestão da qualidade para atingir-se níveis mais altos de satisfação dos consumidores através da colaboração com fornecedores (ROBINSON \& MALHOTRA, 2005). 
Brown (1996) observa alguns pontos necessários para o entendimento e aplicação da gestão da qualidade e seus conceitos, quais sejam: horas dedicadas ao treinamento dos colaboradores, quantidade de equipes em ação; número de funcionários realmente engajados nestas equipes, número de funcionários capazes de citar os valores e missão da organização, quantidade de processos aos quais foram desenvolvidos procedimentos documentados, quantidade de sugestões de melhoria criadas e encaminhadas e número de premiações distribuídas relacionadas à qualidade.

No entanto, são necessárias aplicações práticas referentes à qualidade para que haja efetividade desta metodologia. Nesse âmbito, Azevedo (2007) salienta que os conceitos de Qualidade e sua real importância e eficácia são de amplo conhecimento. Porém, no que tange o real modo de aplicação desse conceito, acreditava-se tratar de algo muito complexo. Contudo, a definição das ferramentas da qualidade e exemplos didáticos de aplicação, tornou fácil a sua aplicação e seu uso foi difundido. O engenheiro japonês Kaoru Ishikawa criou as chamadas "sete ferramentas da qualidade básicas", sendo elas o checklist, gráfico de controle, histograma, diagrama de causa e efeito, gráfico de Pareto, fluxograma e gráfico de dispersão (ADINYIRA et al., 2014).

\section{CUSTOS DA QUALIDADE}

No que diz respeito à implementação de um programa de gestão da qualidade, Juran (1988), observou que há dois tipos de custos referentes a esta pauta. Um destes é o custo inevitável, ou seja, despesas relacionadas à inspeção, pesquisa para qualidade, formação do grupo de qualidade. O outro é o custo evitável - aquele que justifica os custos inevitáveis - pois se refere aos índices de retrabalho, não conformidades, custos de assistência técnica, desperdícios, descartes, entre outros. Ou seja, refere-se aos custos de má qualidade.

Feigenbaum (1994) corrobora o pensamento de Juran, ao definir custos de qualidade como aqueles aplicados à criação e manutenção do programa de controle total da qualidade bem como o payback dos investimentos à medida que as não conformidades diminuem. Ainda nesse sentido, colocou que os custos de má qualidade vêm à tona durante o processo (dentro da empresa) ou, na pior hipótese, quando o produto já está em uso pelo cliente - o que denigre a imagem da empresa e marca. Embora os efeitos negativos resultantes de problemas de qualidade invariavelmente afetam a performance operacional de uma organização, a pior consequência é a potencial perda da satisfação e confiança dos clientes finais (JIRASUKPRASERT et al., 2013).

Devido ao fato dos custos da qualidade corresponderem a uma parcela significante dos custos totais de uma organização, além de um montante considerável do lucro líquido, é imperativo que as empresas os monitorem (AYACH et al., 2019). No entanto, é muito pequeno o número de firmas que mensuram seus custos de qualidade, e as que o fazem não os 
monitoram de forma sistemática (GLOGOVAC \& FILIPOVIC, 2017). Desta forma, a maioria das empresas não utiliza informações relacionadas aos custos de qualidade em seus processos de tomada de decisão (TYE et al., 2011).

\section{MÉTODO DMAIC}

O método DMAIC é uma ferramenta da qualidade que visa à formação de equipes para realização de tarefas de cunho estratégico na empresa (WERKEMA, 2012). O método DMAIC também é considerado uma técnica de solução de problemas (MAST \& LOKKERBOL, 2012), que tem como objetivo reduzir o número de defeitos de produtos e as variações de processo (LINDERMAN et al., 2003).

O método é constituído por cinco fases: (D) Define ou definir: define-se o objetivo em questão; (M) Measure ou medir: busca-se o foco do problema; (A) - Analyze (analisar): buscamse as causas do problema; (I) Improve ou melhorar: buscam-se soluções para o problema; e (C) Control ou controlar: controla-se o problema para se garantir sua eficiência em longo prazo (WERKEMA, 2012).

O método DMAIC é considerado consistente e de bons resultados, pois é dada atenção real ao planejamento - fases de definir, medir, analisar e parte de melhorar - antes de quaisquer ações descabidas ou desnecessárias. Não obstante, crê-se que a existência de roteiro pré-determinado para ação de um projeto é uma ferramenta facilitadora. Com isso, há maiores chances de sucesso em um projeto, visto que, não são necessárias apenas pessoas com conhecimento prévio e consistente do assunto para somar à pauta (WERKEMA, 2012).

\section{RESULTADOS E DISCUSSÃO}

A empresa possui variados setores, responsáveis pela produção de doze linhas de produtos, e mais pedidos especiais. Porém, suas características funcionais são semelhantes, o que implica em processos sem grande variação dos componentes básicos (chapas metálicas, poliuretano injetado, vidros, perfis plásticos, motores, entre outros). Baseado em conceitos de Controle Total da Qualidade, buscou-se ferramentas que pudessem melhorar a atual situação da empresa. No que diz respeito aos problemas observados no SAC - má qualidade dos produtos - propõe-se a aplicação de uma ferramenta conhecida como DMAIC, auxiliada pelo $5 \mathrm{~W} 2 \mathrm{H}$, que tem o intuito de definir critérios acerca do que será trabalhado.

Dessa maneira, houve a primeira definição de forma visualmente clara acerca do que iria ocorrer, que foi colado no mural da sala de reuniões. O problema foi definido (minimizar os custos de assistência técnica) e foram determinados os responsáveis pela realização do projeto, quais sejam os líderes de produção, supervisores, gerência e engenharia. Foi definido também o início das operações, bem como período de tempo no qual haverá reuniões. Ainda, definiu- 
se o motivo principal dessa operação acerca das melhorias, que é o custo médio mensal de $\mathrm{R} \$ 450.000,00$ gastos com assistência técnica. A principal ferramenta usada foi escolhida (DMAIC), tendo sido definidas as origens dos custos de operação.

Figura 1 - Diagrama DMAIC

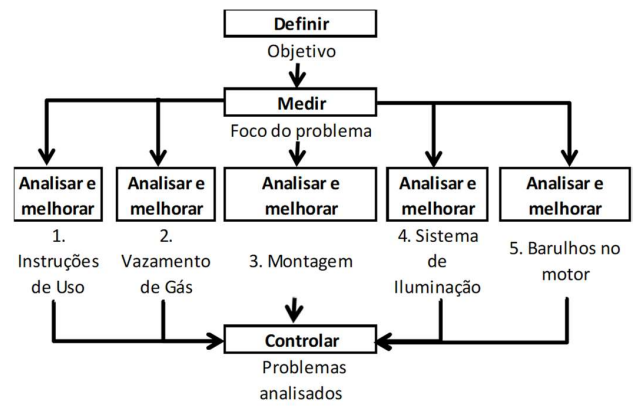

Fonte: os autores

ETAPA D - DEFINE

De acordo com o gráfico da figura 2, graduou-se a importância dos produtos e seus defeitos. A ocorrência de problemas no que diz respeito às instruções de uso alcançou, aproximadamente, 800 vezes no período de dois anos. Instruções de uso juntamente com vazamentos na tubulação de gás, montagem, sistema de iluminação e ruídos no motor, somam um índice aproximado de $70 \%$ das ocorrências. Desta forma, a região salientada na ilustração 10 com a letra $A$, será o foco do trabalho. Seguindo esta ideia, resolvido os problemas de região $A$, trabalhar-se-á em médio prazo na região $B$, e, por conseguinte, na região $C$.

Figura 2 - Importância dos produtos e seus defeitos 


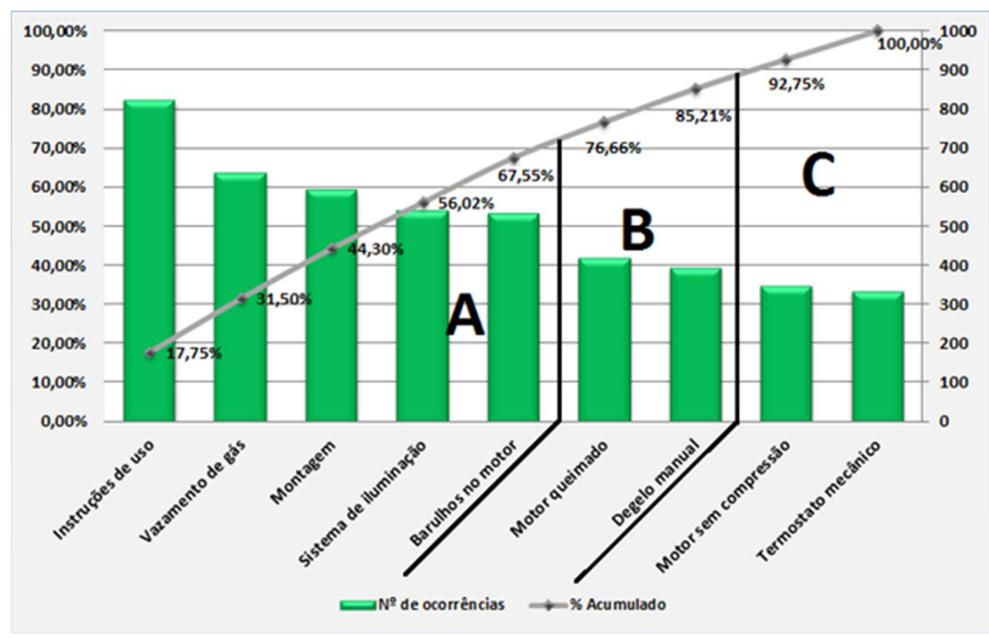

Fonte: os autores

ETAPA A - ANALYZE E I - IMPROVE

Para analisar as causas dos problemas, optou-se por reunir os principais conhecedores práticos desta empresa de refrigeração, os líderes de cada setor. Mesmo sabendo da importância do conhecimento teórico, não há profissionais peritos, como consultores, ao alcance da empresa no momento. Além do que, estes líderes de produção dominam a prática destes processos, sabem as principais causas dos problemas, bem como possíveis soluções, porém mantinham-se desprovidos de recursos pela gerência da empresa até o momento. Nesse âmbito, a partir das cinco principais causas levantadas e selecionadas segundo o gráfico anterior, contatou-se os líderes para reunião, e o principal trabalho ocorrido foi acerca de um brainstorming. Este, ocorrendo tanto de maneira a apontar os erros causadores, bem como em alguns casos já as soluções.

\section{INSTRUÇÕES DE USO}

Referente às instruções de uso, pode-se considerar que o brainstorming ocorreu de maneira involuntária, pois os clientes e técnicos salientaram em quais itens creem que o manual falha no que diz respeito às informações precisas. Essas informações foram analisadas e são consideradas válidas, pois nestes itens ao não ficar clara a informação, ocorreu que o cliente operasse o equipamento de maneira errada.

Da mesma maneira dos POP's (Procedimento Operacional Padrão) os manuais enviados junto aos produtos ficam desatualizados ao longo dos anos. Isto ocorre, basicamente, 
pois os manuais são feitos de maneira genérica. Em uma família de produtos, há em torno de dez produtos com especificações diferentes. A primeira ação a ser tomada é a criação de um manual para cada modelo. Apenas não sendo necessária diferenciação por tamanho, visto que nesses há as mesmas características técnicas e operacionais. Outra ação importante para evitar as ocorrências quanto às instruções, foi a criação de adesivos com especificações relevantes. Isso, pois obteve-se o dado com o SAC que alguns clientes admitiram a não leitura do manual. Com esta ferramenta, salientaram-se instruções básicas, porém de forma clara e atrativa (fonte grande; e usuário não precisa procurar a informação recorrendo ao índice do manual), funcionando como um método a prova de erros.

\section{VAZAMENTOS DE GÁS}

Dentre o processo completo da manufatura de um expositor refrigerado, em três momentos - em diferentes setores - ocorrem atividades com a tubulação (em cobre). Desta forma, precisa-se encontrar em qual destes setores ocorrem as falhas que convirjam nos vazamentos. Desta forma, houve o brainstorming com os funcionários pertinentes ao processo das tubulações, e com os funcionários da engenharia de processos. Nas três fases da manufatura envolvendo estas tubulações foram sugeridas possíveis causas de vazamento de gás.

1 - Solda mal feita: Em dois pontos do processo pode haver vazamento de gás no que tange à solda. Sugeriu-se análise visual da solda, que, mesmo simples, é eficaz. Os líderes de produção admitiram que muitas vezes seus funcionários não detinham atenções à solda. Principalmente, no que se refere à solda no processo de montagem, no qual a tubulação do motor é ligada à tubulação já pré-montada no balcão. Segundo o líder pertinente, não havia acesso visual a toda circunferência da solda, visto que por um lado há o motor bloqueando acesso. Para isso, optou-se por pequeno espelho em haste flexível, na qual é possível dirigir à toda extensão da solda. Também devido a complexidade da operação, solicitou-se ao $\mathrm{RH}$ a exigência de curso técnico em solda para esta atividade.

2 - Detecção de vazamentos: Muitas vezes pequenas falhas nos tubos não eram detectadas no primeiro processo, e peças defeituosas seguiam seu fluxo interno. Para combater isso, no preparo das tubulações instalou-se banheira com água. Assim, quando há dúvidas visuais no que tange pequenos furos, pode-se mergulhar a peça na água e analisar por meio das bolhas se há falhas.

3 - Criação de POP: para que estes testes ocorram de maneira correta, em qualquer uma das três partes do processo, foi sugerido um POP especial para estes. Assim, o que tange a solda ou aos testes, agora está devidamente explicitado nos procedimentos. E caso ocorra, há as medidas a serem tomadas, como descarte de peças na primeira operação, até comunicar supervisor no terceiro processo (montagem) para análise à respeito. 


\section{MONTAGEM}

Nesta fase do projeto, participaram os líderes das linhas de pré-montagem (processo ocorrido antes da peça injetada), e das linhas de montagem. Neste quesito, atualmente ocorrem os mais variados tipos de defeitos, portas não alinhadas, acabamentos mal feitos (feitos muitas vezes com ferramentas manuais), entre outros. Ocorreu desta forma, o brainstorming a respeito das principais causas dos problemas de montagem:

1 - Uso de gabaritos não controlados e não conformes: considerações a respeito do item: informações relevantes, visto que há grande quantidade de gabaritos para montagem de cada produto. Estes, que são feitos sem nenhum controle, com o operador da função confeccionando na marcenaria o gabarito da maneira que julga correta (muitas vezes pequenos tacos sem nenhuma informação). Desta forma, como feitos em madeira ou mdf, sofrem desgaste com a operação diária. Assim, incham ou são danificados com a umidade, o que não garante a precisão milimétrica que o processo necessita. Quando operadores faltam, há casos do substituto usar o gabarito errado. Muitas vezes o erro foi encontrado e foi passível de retrabalho no decorrer do processo. Com o erro não encontrado, possivelmente haverá futura reclamação ao SAC, no item montagem - estrutura e acabamento.

A ação tomada para controle dos gabaritos ocorreu basicamente de duas maneiras. De maneira a extinguir os gabaritos quando possível, houve a alteração por parte da engenharia de processos dos desenhos das peças e programação da puncionadeira. Desta forma, os desenhos foram modificados de maneira a haver marcações (pequenos furos não passantes) nas chapas. Quando enviados para o programador da puncionadeira, este analisa a melhor ferramenta para confeccionar a pequena marcação. Com este trabalho, não há mais necessidade de gabaritos ou qualquer tipo de medição para colocação de reforços nas chapas metálicas, fixação de parafusos, ou fixação de outras peças.

A outra ação tomada para controle dos gabaritos ocorreu de forma a projetar e confeccionar estes de maneira correta. Para isso, levantaram-se os poucos gabaritos que ainda seriam necessários devido à ação anterior (marcações), e houve o desenho no software de cada um destes. Desta forma, os desenhos há uma pasta virtual com todos os desenhos de gabaritos para controle. Ainda nesse trabalho, os projetos destas ferramentas foram encaminhados à serralheria, e depois à pintura. A engenharia de processos tratou de identificar com números, e pequena descrição (à caneta especial que não apaga) da atividade que as peças serão necessárias. Finalizando o processo de controle, nas atividades dos POP's agora são anexadas fotos dos gabaritos das atividades, e os respectivos números.

2 - POP's não atualizados e não claros: considerações a respeito do item: consideração levantada importante. Quando analisado, constatou-se que isto acontece devido aos POP's serem criados junto com os respectivos novos produtos. E, quando alterações no projeto são feitas (que alterem o processo), estas não são repassadas ao POP. Constatou-se, inclusive, que 
ao longo dos anos de ciclo de vida de um produto, acontece muitas vezes de o POP ficar inválido, ou seja, não há condições de se entender e botar em prática as atividades pertinentes.

Outro ponto que foi observado é a forma como os POP's são confeccionados. Estes são elaborados por funcionários da engenharia, que acompanham o processo em linha de montagem. Os líderes de produção, por sua vez, aprendiam o procedimento de maneira superficial pelos criadores dos produtos (P\&D). Quanto aos detalhes, eram definidos com base no conhecimento empírico dos líderes. Desta maneira, estava-se documentando o procedimento na fase errada do processo, onde as informações se perdiam. Optou-se pelos criadores dos procedimentos trabalharem junto aos criadores dos produtos, onde as informações são corretas, claras, e conforme o projeto elaborado. Assim, o novo modelo de POP apresenta mais clareza e é de simples entendimento (anexo em apêndice).

3 - Não é efetuado treinamento adequado para os novos operadores, ou para toda a produção quando há novos produtos: a informação coletada é pertinente, pois no que tange à montagem desconforme dos produtos - o que vem sendo observado no SAC - o treinamento de funcionários é uma medida interessante para combater isto. Visto que, os treinamentos, quando ocorriam, eram de maneira subjetiva e não organizada. Normalmente, esperavam-se dois a três funcionários novos no setor para ocorrer o treinamento por parte da liderança, senão este ocorria na realização das atividades normais, com outro funcionário mais experiente (do posto de trabalho antecedente ou subsequente) auxiliando e tirando as dúvidas.

Para mudar esta situação de despreparo, evitando falhas na montagem, analisaramse novos métodos para treinamentos e controle destes. No que se refere aos novos funcionários, optou-se por treinamento individual de cada entrante. Isso ocorre de forma que o líder auxilia o operador com exclusividade de duas horas iniciais, e atenção ao longo do primeiro dia. O treinamento é feito com o POP auxiliando a tarefa, e este fica à disposição do colaborador para sanar suas dúvidas sempre que necessário.

4 - Líderes não atuam na devida função: esta constatação salientada no brainstorming é de valia. Isso, porque os líderes de produção nesta empresa - aqueles que dominam o conhecimento prático - costumam exercer outras funções, que não cabem ao seu cargo. Por exemplo, estes atuam como abastecedores de peças, como operadores (na falta de outros), entre outras pequenas funções. Nesse âmbito, a produção fica desassistida, falta por horas ao longo do dia de trabalho a experiência capaz de sanar dúvidas, ou sobrepor os percalços. Dessa maneira, fizeram-se reuniões e treinamentos com estes líderes. Foi esclarecido, por exemplo, que na falta de operadores, o líder deveria contatar o gerente de produção. Dessa forma, este deve alocar outro operador para a função de montagem, mesmo que isso confrontasse a antiga política da organização.

5 - Peças são danificadas no transporte: esta constatação ocorria devido aos modos errados de transporte de peças. Peças misturadas e sem identificação eram jogadas em carro 
inadequado para o transporte. Além de que, havia partes do chão da fábrica em condições não apropriadas, desse modo peças vinham a cair do utensílio de abastecimento. Contudo, no processo da montagem, as peças muitas vezes não estavam conformes. Porém, sem uma gestão apropriada, a peça era retrabalhada pelo próprio montador (uso de ferramentas como martelo, serrote, pé-de-cabra, entre outras), o que vinha a atenuar o problema. O que ocorria, no entanto, é que muitas vezes o problema vinha à tona para o consumidor final.

As ações tomadas para se resolver isso foram focadas no sistema de abastecimento. Os antigos carros ou paleteiras foram substituídos por outros, projetados pela engenharia exclusivamente para cada tipo de peça. A forma em que a peça era transformada também foi analisada, visando menor probabilidade de avaria. Tiras de chapas metálicas, por exemplo, que são anexadas somente no processo de montagem, antes eram transportadas de maneira vertical, escoradas nas paredes do carro. Isso não garantia a precisão e integridade da peça, devido a um ângulo, pois a peça era escorada. Agora, com nova maneira de transporte, a peça passou a ser transportada deitada, uma sobre a outra. Além de que, são fixados pedaços de espuma ou papelão no carro transportador, evitando arranhões e amortecendo os impactos.

\section{SISTEMA DE ILUMINAÇÃO}

Observou-se que há grande índice de ocorrências de assistência no que tange o sistema de iluminação. Dessa forma, houve o brainstorming com intuito de levantar os problemas que ocorrem. No entanto, pela primeira vez na realização do deste, tratou-se de um fator preponderante das falhas. Bem como, o que já vinha sendo levantado pelos assistentes técnicos, o do sistema reator e lâmpada fluorescente.

1 - Sistema reator e lâmpada fluorescente: esta constatação feita durante o brainstorming é considerada válida. Pois, junto ao SAC, referindo-se ao sistema de iluminação, estes componentes já eram tidos como causa das ocorrências, de acordo com a assistência técnica. Optou-se então por buscar possível solução que viesse a resolver a questão do sistema de iluminação. Desta forma, analisando os componentes do sistema, deteve-se atenção à fragilidade de certas peças, principalmente, os reatores. Este componente, fabricado em empresa de Caxias do Sul, apresenta pequenas soldas, fixando a capa metálica, e, na sua maioria, os fios. Muitas vezes, neste frágil componente, notam-se falhas assim que estes chegam do fornecedor, principalmente fios soltos dentro da embalagem. Acredita-se, portanto, que devido ao transporte estes componentes são avariados. Não aquém disso, mesmo que devidamente processados e instalados dentro desta empresa de refrigeração comercial, ocorriam estas falhas no transporte do equipamento para o consumidor final. Bem como, as lâmpadas fluorescentes, muitas vezes, vinham a quebrar.

Decidiu-se, portanto, que o sistema lâmpada fluorescente/reator deveria ser revisto. Analisou-se a possibilidade de rever com o fornecedor a qualidade dos componentes (no que 
tange à solda), e, até mesmo, a possibilidade de se trocar o fornecedor. Porém, em meio a estas análises e estudos a respeito, surgiu a ideia de troca de todo o sistema de iluminação. Havia a possibilidade de troca por um sistema de iluminação com fitas de led. Contudo, analisou-se o modo construtivo e funcional dessa nova possibilidade, bem como, o custo que acarretaria esta troca. Constatou-se por meio das pesquisas técnicas, que o principal componente causador das assistências técnicas - o reator - tendo em vista o sistema de iluminação, não se faria mais necessário com a aplicação dos leds. No entanto, este seria substituído pela fonte de $2 \mathrm{~A}$, produto de maior simplicidade, porém, resistência acerca dos componentes. Em contrapartida, agrega maior custo ao sistema, o que não foi aceito pela direção.

\section{BARULHOS NO MOTOR}

Para se resolver este problema também de grande relevância ao SAC, precisou-se trabalhar no brainstorming com todos os líderes de produção da empresa, buscando qualquer tipo de falha que convirja em ruídos. No entanto, trabalhou-se com atenções voltadas ao líder da montagem e instalação dos motores, por estes serem as fontes dos ruídos (compressor e o motor elétrico estão juntos em uma mesma carcaça - herméticos). Contudo, neste setor ocorrem também os testes, com os quais muitas vezes são levantados estes problemas de barulhos nos equipamentos antes que sejam expedidos. Desta forma houveram os apontamentos e as posteriores análises e considerações:

1 - Motor com mola interna quebrada: esta ocorrência, sem dúvidas, é culpa do fornecedor. Isso porque, enclausurada em carcaça hermética, essa mola provavelmente é muitas vezes mal soldada ou fixada pelo fornecedor. Porém, devido a esta peça mal fixada, juntamente com o ruído tradicional dos motores, foi salientado por cliente que inclusive os vizinhos do estabelecimento reclamaram do barulho, bem como seus próprios clientes. Dessa maneira, quando constatada a falha da peça dentro da empresa, essa logo é trocada, e é enviado pedido de reposição ao fornecedor. Porém, quando ocorre o problema no cliente final, só é trocada (sem custos ao cliente) a unidade no período de garantia da peça oferecida pelo fabricante, ou seja, um ano.

Este tipo de ocorrência não era considerado importante para a empresa, visto que não era falha sua, e sim do fornecedor. Porém, passou-se a considerar que nos balcões refrigerados, consta o nome desta empresa de refrigeração. Portanto, nesse âmbito a marca perde confiança, qualidade, respeito e clientes, ainda que, a assistência explicasse o motivo real do problema.

Para minimizar isto, optou-se por um simples método de inspeção no processo fabril assim que a embalagem dos motores é aberta. Com um pequeno balançar do motor, constatase se há pequeno ruído, oriundo dessa mola interna solta ou mal fixada. Isso ocorre, portanto, antes da instalação e teste do aparelho funcionando (em alguns casos o defeito pode ser 
constatado assim). Desta forma se reduz custo e tempo de instalação.

Para resolver a raiz do problema, optou-se pelo seguinte trabalho junto ao fornecedor. Envia-se o registro destas ocorrências para o SAC do fornecedor ficar ciente destes problemas e tentarem resolvê-lo. Senão, em reunião com o gerente de compras e com o vendedor desta empresa de motores, ficaram esclarecidos alguns pontos. Foi acordado com o fornecedor o período de dois meses para readequar seu projeto naquilo a diminuir este índice de ocorrência do SAC.

2 - Borracha de amortecimento solta: juntamente com o item a respeito da mola interna do motor, este também diz respeito ao fornecedor. Visto que o motor tem faces arredondadas, este vem do fornecedor já fixado em uma base. Para essa fixação são usados parafusos, arruelas, e pedaço de borracha para amortecimento (não comparado à arruela de borracha). Desta maneira, com a peça de borracha, não há contato direto metal com metal, não havendo barulho. Porém, o problema trata-se da simplicidade e fragilidade desta peça. Com o uso do refrigerador, principalmente se é em locais úmidos, ou mesmo com incidência de sol, a borracha amortecedora resseca. Então, em pouco tempo de uso, os ruídos começam. A atividade de assistência dessa peça é simples: o técnico solta o parafuso, e instala novo pedaço de borracha qualquer, sem custo de material normalmente. Sabe-se, no entanto, que independente do custo com material, o custo com a chamada do técnico é sempre o mesmo. Dessa forma, tratou-se em reunião com o fornecedor também a instalação de peça de amortecimento mais resistente, como por exemplo, arruela de borracha.

Ainda sobre emprego de material para amortecimento no que tange o controle de ruídos, há outra peça que foi usada nesse sentido. Estas são feitas usando-se sobras de material das chapas plásticas de PSAI (não há aumento de custo de material), em um formato de 200 $\mathrm{mm}$ de comprimento e $30 \mathrm{~mm}$ de largura. Dessa forma, são instaladas entre a base do motor, e as esperas de fixação deste no produto. Sendo de PSAI, não ressecam ou estragam com facilidade, e absorvem o impacto do motor/compressor em mais um ponto.

\section{ETAPA C - CONTROL}

De acordo com o controle às ações tomadas durante a aplicação do DMAIC, salientase a realização de reuniões acerca do assunto. Estas ocorrem quinzenalmente, pois nem toda semana são fabricados alguns produtos cabíveis de observação, bem como, em um mês pode se perder o controle à respeito. Essas reuniões são tratadas de forma simples, com tópicos acerca dos determinados assuntos tratados. No tópico montagem, por exemplo, são tratados todos os subitens sugeridos e trabalhados durante a fase analisar e melhorar do DMAIC. Dessa forma, cada colaborador (líderes, supervisores, gerentes e engenharia) dá seu parecer a respeito do assunto, no sentido de um brainstorming, seja favorável ou não acerca das decisões tomadas. 
No que diz respeito à qualidade dos produtos oriundos de terceiros, adotou-se método para controle. Pois, estes também foram tratados como causas dos problemas de assistência técnica. Em dois pontos do item analisar do DMAIC, compressor e sistema de iluminação, haviam falhas do fornecedor. Portanto, criou-se ficha para avaliação. Com este tipo de avaliação dos produtos e fornecedores, passa-se a haver maior controle destes. Assim, quando levantada possível falha do fornecedor ao longo do processo, os líderes podem requerer a ficha a seus supervisores. Desta forma, líder e supervisor realizam teste (caso ainda não esteja claro o defeito). Estes, portanto, se encarregarão de levar a ficha preenchida com as devidas explicações às reuniões de controle do DMAIC. Então, repetindo-se a fase analisar e melhorar, o núcleo do DMAIC transmitirá os levantamentos acerca da falha ao fornecedor. Este, portanto, terá prazo estipulado para se pronunciar a respeito, e, comprometer-se em corrigir sua falha. Caso a solicitação não seja atendida, trocar-se-á de fornecedor daquela peça.

Nesse âmbito, conforme o ciclo das alterações dos produtos (internos ou externos) acontecerem, estas serão apresentadas nessas reuniões. Em análise entre todas as partes que trabalharam a fim de melhorar os índices apontados no SAC, no que tange o núcleo que tratou de acordo com a ferramenta de qualidade DMAIC, acordaram-se os prazos. Cada responsável (tem conhecimento acerca do seu micro processo) analisou as datas e deu seu parecer de tempo. Foi levado em consideração tempo de alteração de projetos, produção, venda para representante, venda para consumidor final e tempo de possível desgaste (período de garantia total do produto em que está coberto por assistência técnica - três meses). Assim, o período de quatro meses foi estabelecido como prazo de resposta acerca das melhorias implantadas, seja favorável ou não. Dessa forma, corroborar-se-ão as mudanças apontadas e estas serão apresentadas ao grupo. Caso a resposta não seja positiva, e o problema que atualmente é reclamado ao SAC continue a ocorrer, estes serão retrabalhados. Assim, reiniciar-se-á o ciclo do DMAIC.

\section{CONCLUSÃO}

O objetivo geral deste trabalho foi atingido. Identificou-se as principais reclamações via SAC e propôs-se soluções para as mesmas: revisão dos POPs, controle de fornecedores, controle de gabaritos, treinamentos com os operadores, e troca de componentes falhos. Mesmo enquanto as ações estavam em implantação, quanto ao período posterior à elas, foi possível identificar redução das ocorrências do SAC. A satisfação do cliente também vem aumentando, no sentido que há maior confiabilidade no processo, porém ainda não há instrumento para mensurá-la.

Mesmo com o curto período no qual os novos projetos foram colocados em prática, já houveram respostas positivas. Por exemplo, houve diminuição das ocorrências no que diz respeito a problemas no sistema de iluminação (defeito muitas vezes era notado pelo cliente 
assim que ligava o produto), já que houveram trocas de componentes pela empresa de refrigeração. Desta forma, as ocorrências vêm diminuindo, bem como, os custos de assistência técnica.

Como sugestão para trabalhos futuros (período entre seis meses a um ano para poder haver feedback completo dos clientes acerca de todas as alterações) há a quantificação das melhorias efetuadas neste. Isso pode ocorrer no que diz respeito à análise do número de ocorrências do SAC, antes e depois deste trabalho. Bem como, a análise financeira que as melhorias implicaram. De forma a comparar o futuro custo médio mensal das assistências técnicas, com o atual de $\mathrm{R} \$ 450.000,00$.

\section{REFERÊNCIAS}

ABNT - ASSOCIAÇÃO BRASILEIRA DE NORMAS TÉCNICAS. NBR ISO 9000: Sistemas de gestão da qualidade - Fundamentos e vocabulário. Rio de Janeiro, 2000.

ADINYIRA, E.; AYARKWA, J.; AIDOO, I. Knowledge and usage of the Seven Basic Quality Control tools by producers of precast concrete products in Ghana. Kumasi: Journal of Construction Project Management and Innovation, v. 4 (2), pp. 966-975, 2014.

AYACH, L.; ANOUAR, A.; BOUZZINI, M. Quality Cost Management in Moroccan Industrial Companies: Empirical Study. Casablanca: Journal of Industrial Engineering and Management, v. 12 (1), pp. 97-114, 2019.

AZEVEDO, Rafael Guedes de. Melhoria do forneamento de biscoitos em forno à lenha com processo de batelada. 2007. 86 f. Dissertação apresentada ao Programa de Pós-Graduação em Sistemas e Processos Industriais - Mestrado, Área de concentração em Controle e Otimização de Processos Industriais, Universidade de Santa Cruz do Sul - UNISC, Santa Cruz do Sul, 2007.

BASTAS, A.; LIYANAGE, A. Sustainable supply chain quality management: A systematic review. Derby: Journal of Cleaner Production, v. 181, pp. 726-744, 2018.

BROWN, Mark Graham. Por que o TQM falha e como evitar isso. São Paulo: Nobel, 1996.

CARVALHO, M. M., PALADINI, E. P. Gestão da Qualidade - teoria e casos. Rio de Janeiro: Campus, 2005.

CIERCO, A. A. et al. Gestão da qualidade. 10 ed. Rio de Janeiro: FGV, 2011.

FALCONI, V. TQC: Controle da Qualidade Total no Estilo Japonês. 9. ed. Nova Lima: Falconi, 2014.

FEIGENBAUM, Armand Vallin. Controle Total da Qualidade. Tradução: Regina Cláudia Loverri. 40. Ed. São Paulo: Makron Books do Brasil, 1994. 
GAVA, A. J; FRIAS, J. R. G; SILVA, C. A. B. Tecnologia de alimentos, princípios e aplicações. São Paulo: Nobel, 2009.

GIL, A. C. Como elaborar projetos de pesquisa. 5. Ed. São Paulo: Atlas, 2010.

GLOGOVAC, M.; FILIPOVIC, J. Quality costs in practice and an analysis of the factors affecting quality cost management. Belgrade: Total Quality Management \& Business Excellence, v. 29 (13), pp. 1521-1544, 2018.

MAST, J.; LOKKERBOL, J. An analysis of the Six Sigma DMAIC method from the perspective of problem solving. Amsterdam: Int. Journal of Prod. Economics, v. 139, pp. 604-614, 2012.

JIRASUKPRASERT, P. et al. A Six Sigma and DMAIC application for the reduction of defects in a rubber gloves manufacturing process. Coventry: International Journal of Lean Six Sigma, v. 5 (1), pp. 2-21, 2014.

JURAN, Joseph Moses. Planejando para a Qualidade. São Paulo: Pioneira, 1988.

KUMAR, S. DESHMUKH, R. Commercial Refrigeration Market by Product Type (Deep Freezers, Bottle Coolers, Storage Water Coolers, Commercial Kitchen Refrigeration, Medical Refrigeration, Chest Refrigeration, Others), and End-User (Full Service Restaurant \& Hotels, Food Processing Industry, Hospitals, Retail Pharmacies, Supermarket/Hypermarket, Convenience Stores, Quick Service Restaurants and Others): Global Opportunity Analysis and Industry Forecast, 2019 -2026, 2019. Disponível em:

https://www.alliedmarketresearch.com/commercial-refrigeration-market. Acesso em: 24 de março de 2020.

LINDERMAN, K. et al. Six Sigma: a goaltheoretic perspective. Journal of Operations Management, v. 21, pp. 193-203, 2003.

MIGUEL, Paulo Augusto Cauchick. Metodologia de pesquisa em engenharia de produção e gestão de operações. 1. Ed. Rio de Janeiro: Elsevier, 2010.

ROBINSON, C. J.; MALHOTRA, M. K. Defining the concept of supply chain quality management and its relevance to academic and industrial practice. Columbia: Int. J. Prod. Econ., v. 96 (3), pp. 315-337, 2005.

RODRIGUES, M. V. Ações para a Qualidade. 3. Ed. Rio de Janeiro: Qualitymark, 2010.

SELEME, R.; STADLER, H. Controle da Qualidade: as ferramentas essenciais. 2. Ed. Curitiba: Ibpex, 2010.

STEFAN, L., YVONNE, L. Trust and quality management: perspectives from marketing and organizational learning. Trollhättan: Total Quality Management \& Business Excellence, v. 23 (1), pp. 13-26, 2012.

TRANSPARENCY MARKET RESEARCH. Commercial Refrigeration Equipment Market - Latin America (Caribbean, Central America and South America) Industry Analysis, Size, Share, 
Growth, Trends and Forecast 2012-2018. 2013.

TYE, L. H.; HALIM, H. A.; RAMAYAH, T. An exploratory study on cost of quality implementation in Malaysia: The case of Penang manufacturing firms. Penang: Total Quality Management, v. 22 (12), pp. 1299-1315, 2011.

WERKEMA, Cristina. Criando uma Cultura Lean Seis Sigma. 3. ed. Rio de Janeiro: Elsevier, 2012. 